\title{
REDUCTION OF SUPRAGINGIVAL PLAQUE ACCUMULATIONS IN INSTITUTIONALIZED DOWN'S SYNDROME PATIENTS BY PERIODIC TREATMENT WITH TOPICAL KANAMYCIN
}

\author{
W. J. LOESCHE and D. NAFE \\ University of Michigan, School of Dentistry, Ann Arbor, Michigan and Plymouth \\ State Home and Training School, Northville, Michigan, U.S.A.
}

\begin{abstract}
Summary-A small group of institutionalized Down's syndrome patients were treated with topical kanamycin sulphate paste, once or twice a day for 3-5 days, every fifth week over a 52-week-period. The teeth were not brushed during this 52-week-period. The wet weight of the supragingival plaque in the kanamycin group was significantly reduced when compared to the supragingival plaque formed in the group receiving a placebo paste. The gingivitis score of the kanamycin group did not deteriorate during the period of antibiotic administration despite the absence of oral hygiene procedures. No increase in kanamycin-resistant bacteria or yeasts were detected in plaque or tongue samples during the period of kanamycin treatment.
\end{abstract}

\section{INTRODUCTION}

MANY mentally handicapped, institutionalized children have bacterial plaque accumulations which lead to periodontal disease at an early age (BROWN, LEVIN and CUNNingham, 1961; SWALlow, 1964; SZNAJDER et al., 1968; LoesCHe et al., 1971; CUTRESS, 1971). This situation may be attributed to the fact that most of these individuals are not capable of brushing their own teeth and that the dental manpower available at these institutions is not adequate to provide effective toothbrushing and prophylaxis of the residents. These difficulties are of sufficient magnitude that it is unlikely that they can be solved by conventional hygiene procedures, even allowing for a generous increase in capital to cover the cost of oral therapists.

New approaches to the control of oral health in these handicapped individuals are needed. The recent experimental evidence that the mass of bacteria, which reside on the dental gingival surfaces, may be dependent upon the presence of specific plaqueforming organisms (GibBons et al., 1966; KraSSE et al., 1968; SocranSKY, HubersaK and Propas, 1970; JoRdan and Hammond, 1972) offers the possibility of a chemotherapeutic approach aimed at the elimination of these specific bacteria (ENGLANDER and KeYes, 1971; JoRdan and DePaola, 1972). With this in mind, a clinical trial of topical kanamycin as a means of improving oral health in mentally retarded individuals was undertaken (LOESCHE et al., 1971). The results were partially successful in that a 5-day-treatment, in which kanamycin was applied to the dental gingival surfaces in the morning, afternoon and evening, had a residual effect that lasted between 4 and 8 weeks post-treatment. At 4 weeks post-treatment, in the absence of 
any other oral hygiene procedures, the kanamycin had reduced supragingival plaque accumulations significantly and had lowered the gingivitis score from preantibiotic levels. The effect of the antibiotic disappeared with time. This study raised the question as to what effect retreatment with kanamycin would have on maintaining the oral health of these subjects.

\section{Subjects}

\section{MATERIALS AND METHODS}

Down's syndrome individuals institutionalized at the Plymouth State Home and Training School, Northville, Michigan, served as subjects. These individuals were residents in four wards of the same dormitory. Thirteen males and two females ranging in age from 7 to $14 \mathrm{yr}$ were included in the study. They exhibited low caries prevalence, averaged about $4 \mathrm{mg}$ of plaque per reference tooth, and had moderate to severe gingivitis. The subjects were randomly assigned to either the kanamycin or placebo group. However, data obtained from two children in the kanamycin group and one child in the placebo group were subsequently omitted from the calculations, as the ability of these children to form plaque and calculus differed markedly from the other subjects (Table 1). Certain subjects

TABLE 1. Distribution OF SUBHECTS ACCORDING TO AMOUNT OF SUPRAGINGIVAL PLAQUE FORMED 5 WEEkS AFTER AN ORAL PROPHYLAXIS

\begin{tabular}{lcl}
\hline & $\begin{array}{c}\text { Plaque wet weight } \\
\text { per reference } \\
\text { tooth (mg) }\end{array}$ & Clinical diagnosis \\
\hline Subject & 0.5 & Slow plaque former \\
R.H. & 0.6 & Slow plaque former \\
G.L. & 1.63 & Moderate plaque former \\
G.S. & 1.82 & Moderate plaque former \\
C.S. & 2.26 & Moderate plaque former \\
D.T. & 2.91 & Moderate plaque former \\
K.A. & 2.96 & Moderate plaque former \\
D.B. & 2.98 & Moderate plaque former \\
A.C. & 4.21 & Heavy plaque former \\
J.P. & 4.28 & Heavy plaque former \\
B.S. & 4.68 & Heavy plaque former \\
L.M. & 5.1 & Heavy plaque former \\
D.S. & 6.39 & Heavy plaque former \\
L.G. & 7.2 & Heavy plaque former \\
J.O. & 17.2 & Rapid calculus former \\
\hline
\end{tabular}

received systemic antibiotics for medical purposes during the 52-week-period covered by this investigation. This treatment invariably improved the oral health of the subjects, and data obtained during these periods of medication were omitted from the calculations. On occasion, the subjects were not available for examination due to leave of absence, quarantines or attendance in class. These factors account for the variability in subject number shown in Table 2.

\section{Plaque and gingivitis measurements}

The six reference teeth (RAMFJORD, 1959), i.e. maxillary right first molar, maxillary left central incisor, maxillary left first premolar, mandibular left first ntolar, mandibular right central incisor and mandibular right first premolar were scored by a double-blind technique for plaque and gingivitis using modifications of the indices developed by LöE (1967). The appearance of the plaque was used to cstimate the range in which the score would fall, i.e. no plaque visible, $0-1 ;$ small to moderate amounts of plaque visible, >1-2; large amounts of plaque visible, $>2-3$; and in rare instances, when the plaque was extremely thick and practically covered the entire tooth surface, a score of 4 was given. Then the amount of plaque removed by a periodontal scaler from the buccal or labial aspect of the tooth was subjectively evaluated, and used to assign the final score within that range. Plaque scores intermediate between the Löe indices were given, i.e. 1.5 and 2.5. The same two investigators scored each buccal or labial surface simultaneously. Agreement on the score was usually obtained but, if 
TABLE 2. EFFECT OF PERIODIC APPLICATIONS OF TOPICAL RANAMYCIN ON PLAQUE WET WEIGHT PER REFERENCE TOOTH*

\begin{tabular}{|c|c|c|c|c|}
\hline $\begin{array}{l}\text { Time in } \\
\text { weeks after } \\
\text { prophylaxis }\end{array}$ & $\underset{\text { group }}{\text { Kanamycin }}$ & $\begin{array}{l}\text { Placebo } \\
\text { kanamycin } \\
\text { group }\end{array}$ & \multicolumn{2}{|c|}{$\begin{array}{l}\text { Significancet } \\
\text { kanamycin vs } \\
\text { placebo }\end{array}$} \\
\hline 0 & \multicolumn{2}{|c|}{$2.9 \pm 1 \cdot 8 \S \quad 3.6 \pm 2 \cdot 0$} & $\mathrm{NS}_{+}^{+}$ & $n=10$ \\
\hline 5 & \multirow{2}{*}{\multicolumn{2}{|c|}{$\begin{array}{cc}2.8 \pm 1.0 & 4.0 \pm 1.7 \\
\text { kanamycin } & \text { placebo } \\
1.4 \pm 0.6 & 4.1 \pm 1.7 \\
1.9 \pm 0.6 & 3.9 \pm 1.4\end{array}$}} & NS & $n=10$ \\
\hline $\begin{array}{l}10 \\
15\end{array}$ & & & \multicolumn{2}{|c|}{$\begin{array}{l}p=0.01 n=9 \\
p=0.02 n=10\end{array}$} \\
\hline $\begin{array}{l}20 \\
25 \\
30 \\
35 \\
40 \\
45 \\
52\end{array}$ & \multicolumn{2}{|c|}{$\begin{array}{l}0.9 \pm 0.7 \\
1.2 \pm 0.6 \\
1.3=0.4 \\
\text { No drug } \\
3.4+2.4\end{array}$} & $\begin{array}{l}\text { NS } \\
\text { NS } \\
\text { NS }\end{array}$ & $\begin{array}{l}n=9 \\
n=9 \\
n=9\end{array}$ \\
\hline
\end{tabular}

* Reference teeth: $3,9,12,19,25,28$.

+ Student $t$-test.

\pm Not significant.

$\$ \mathrm{Mg}$ wet weight plus or minus standard deviation.

differences in opinion occurred, the values were averaged. The ability of this scoring system to reflect plaque mass was subsequently determined as the plaque which was removed from the reference teeth was pooled and weighed (Fig. 1).

The modification of the gingivitis index again involved a consensus scoring system. When the investigators were not in agreement, an average of the two values was recorded. The score given was for the entire buccal-gingival or labial-gingival margin and did not involve the lingual gingiva. The amount of bleeding which occurred when the supragingival plaque was being removed was noted and used to formulate the gingivitis scores. In a fcw instances, the gingivitis was so scverc that a score of 4 was given.

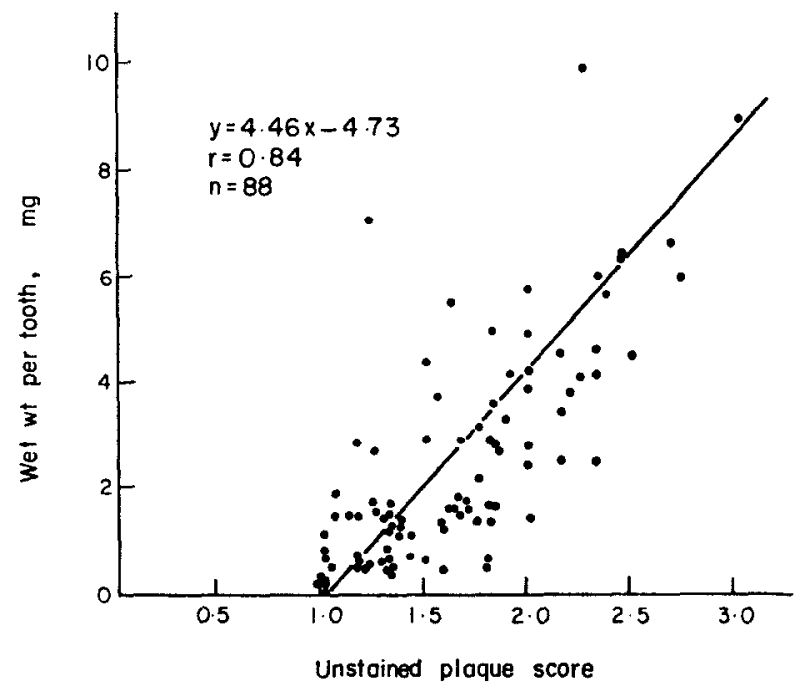

FIG. 1. Correlation between plaque wet weight and unstained plaque score made on institutionalized Down's syndrome patients. 
After the subjective scoring was complete, the supragingival plaque from the six teeth was transferred from the scalers to a preweighed piece of aluminium foil. The wet weight of the plaque was determined within 1 min after collection, using a Roller Smith Precision Balance (Model L6) with a full scale reading of $100 \mathrm{mg}$. This scale is accurate to $\pm 0.05 \mathrm{mg}$. Delay in obtaining this reading was avoided, because the dehydration of the plaque would give erroneous plaque weights. Immediate wet weight determinations of plaque correlated significantly with plaque dry weights in this population, i.e. $r=0.92$ (LOESCHE and GrEeN, 1972). The weight of the pooled plaque sample was divided by the number of reference teeth to give an average weight per reference tooth. This value was used in the various calculations.

\section{Bateriological procedures}

Plaque samples and tongue swabs from each child were cultured at each 5-week examination period with few exceptions. The plaque and tongue swabs were each placed in $10 \mathrm{ml}$ of a reduced transport fluid (RTF) containing 0.02 per cent dithiothreitol (DTT) and $0.001 \mathrm{M}$ ethylenediamine tetra acetic acid (SYED and LOESCHE, 1972) and returned to the bacteriology laboratory. The plaque was dispersed by ultra-sound for $10 \mathrm{sec}$ using a Sonifier micro-tip with a setting of 6 (Heat Systems-Ultrasonic Inc.) and then introduced into an anaerobic chamber where it was serially diluted in the RTF and appropriate dilutions plated on Sabouraud agar and MM10 medium (LOESCHE, HockeTT and SYED, 1972) with and without 0.05 per cent kanamycin sulphate. The MM10 medium is a 0.2 per cent trypticase, 0.05 per cent yeast extract, 2 ner cent sheep blood medium supplemented with the known nutrient requirements of the oral flora. The Sabouraud plates were removed from the chamber and incubated aerobically. The yeast colonies, which grew on these plates after several days of incubation, were counted and recorded per $\mathrm{mg}$ wet weight of plaque. The colonies on the MM10 medium were counted after 1 week. The growth on the MM10 medium without kanamycin refiected the total viable count of the plaque samples, whereas the growth on the MM10 medium with kanamycin represented the number of colony forming units which were resistant to $1 / 100$ th of the clinical dose of kanamycin. The kanamycin-resistant colonies were recorded either as the number of colony forming units per mg plaque wet weight, or as a percentage of the viable count. This level of kanamycin, i.e. 0.05 per cent, was chosen, so that if drug-resistant organisms increased in the cultures, there would still be a margin of safety in the in vivo situation, where 5 per cent kanamycin was used. Thus the clinical trial could be suspended prior to the appearance of clinical symptoms.

The tongue swabs were manipulated on the bench top. The tube containing the swab was agitated for $30 \mathrm{sec}$ with a Vortex Mixer and then serially diluted in the RTF. Samples of $0.05 \mathrm{ml}$ were plated on the Sabouraud and MM10-0-05 per cent kanamycin media and the plates were incubated aerobically and anaerobically respectively. The number of colony-forming units were reported on a per tongue swab basis.

\section{Treatment schedule}

The subjects were seen at 5 week intervals. At the initial visit (" 0 week" in Tables), plaque and gingivitis scores and plaque wet weight were determined. The subjects were given an oral prophylaxis within the next few days which included some subgingival scaling. The attendants in their wards were instructed not to brush the teeth of these children. The subjects were randomly assigned to the two treatment groups, i.e. 5 per cent kanamycin (kanamycin sulphate, Bristol Laboratory, Syracuse, N.Y.) in Orabase (Davies Rose Hoyt, Needham, Mass.) or Orabase alone. The scores obtained from the 0 time exam showed that the groups were similar in regard to plaque wet weight, unstained plaque score, and gingivitis score, Tables 2-4. After 5 weeks, the children returned to the clinic and the various parameters were measured. These values reflected changes due to the prophylaxis, and also gave an indication of the amount of plaque that formed in 5 weeks without brushing. At this visit, each subject was given either one of the two treatments on a double-blind basis. The drug or placebo paste was applied with a cotton applicator to the buccal and labial dental-gingival surfaces in the morning and evening for 5 consecutive days. Two members of the investigating team applied all the treatments during the course of the study. The taste of the Orabase Emollient and the method of application were well accepted by all but one subject. Approximately $1.0 \mathrm{~g}$ of kanamycin sulphate per treated subject was administered during this 5-day-period. The subjects were seen in the clinic 5 weeks later, and the gingivitis and unstained plaque scores and plaque wet weight were determined. The treatment was decreased to nine applications, and the children were re-examined in 5 weeks. This 5 week cycle was repeated six more times, the only change being a reduction in treatment to three applications, which were given on three consecutive evenings. After week 15, the children in the 
TABle 3. EFFeCt OF PERIOdic applications of topical KANAMYCIN ON UNSTAINED PLAQUE SCORES

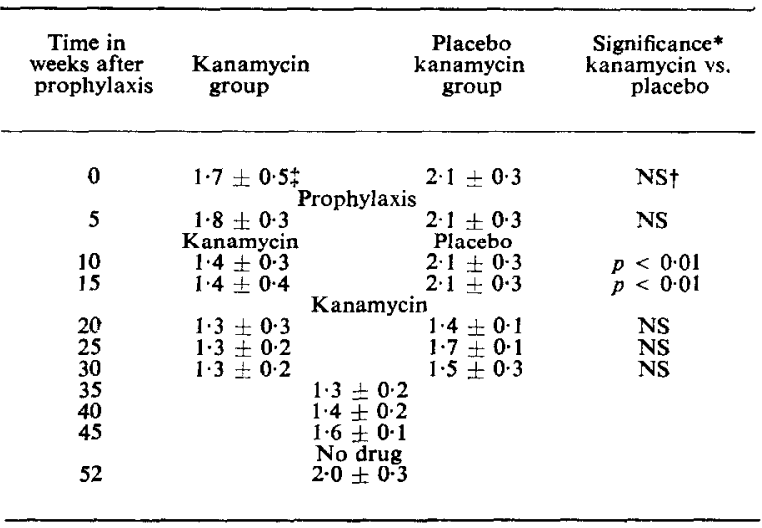

\footnotetext{
* Student $t$-test.

+ NS-no significant.

$¥$ Average plus or minus standard deviation.
}

placebo group also received kanamycin therapy. At week 40 , plaque was removed from the upper right first premolar, the upper right central incisor, the upper left first molar, the lower left first premolar, the lower left central incisor and the lower right first molar in children who had been on kanamycin since week 5 . These teeth had not been mechanically cleaned since the prophylaxis at the beginning of the study and the weight obtained reflected the amount of plaque which had accumulated during the 35-week-period of kanamycin treatment. At week 45, the treatment was omitted to determine if there would be a rebound in plaque formation. The subjects were not observed in the between visit period except for random visits to the wards to reinforce the "no toothbrushing" instructions. To the best of our knowledge, the subjects' teeth were not brushed during this 52-week-period. Exceptions might have occurred, however, if the subjects went home for short visits.

TABle 4. EFFECT OF PERIODIC aPPLICATJONS OF tOPICAL KANAMYCIN ON GINGIVITIS SCORES

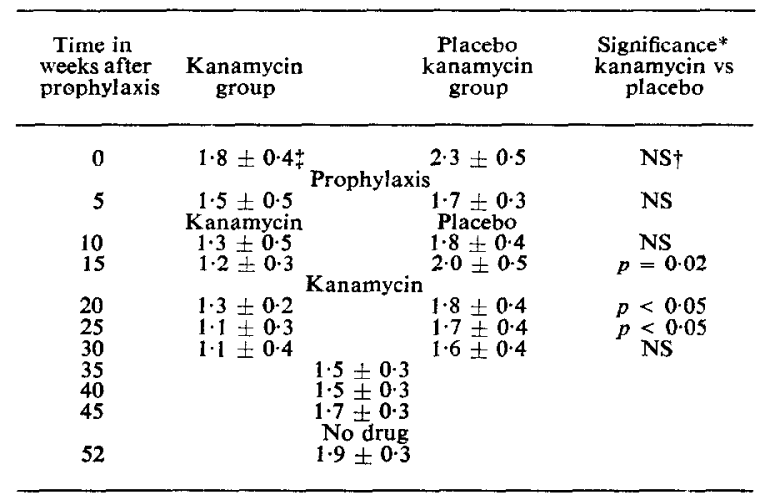




\section{RESULTS}

The subjects had an unstained plaque score (UPS) of $2 \cdot 1 \pm 0.6$ and a gingivitis score (GS) of $2.0 \pm 0.6$ at the initial visit ( 0 week). The pooled plaque removed from the six reference teeth averaged $22.4 \pm 16.0 \mathrm{mg}$ wet weight. This amount of plaque can be easily removed and weighed, with any loss in weight due to manipulation of the sample comprising a small percentage of the total plaque weight. The amount of plaque removed per tooth was determined, and correlation matrices were calculated between this value and either the UPS or GS. The correlation between wet weight and the UPS for five to six measurements on each of the subjects obtained during the course of the investigation is shown in Fig. 1 . The correlation was highly significant with an $r$ value of 0.84 over the range of $1.0-3.0$ on the UPS scale. This would seem to indicate that, when the plaque index was modified to include an approximation of the amount of plaque removed from a tooth by a scaler, a reliable estimate of the plaque wet weight can be obtained. One unit in the UPS range of 1.0-3.0 was equivalent to about $4 \mathrm{mg}$ of plaque wet weight. Our subjects never exhibited an UPS below $1 \cdot 0$, presumably because their teeth were not being brushed. The GS at each 5 -week period correlated significantly with the plaque wet weight with the 95 per cent confidence limit for $r$ falling in the range from 0.42 to 0.9 . When the UPS and the GS were compared at each 5-week period with each other, the correlation coefficient also was significant, i.e. the 95 per cent confidence limit for $r$ fell in the range of $0.55-0.85$. These data show that the modified UPS and GS were in agreement with the objective weight measurement and would indicate the reliability of these clinical scores in evaluating plaque mass in the present investigation.

The subjects differed in the amount of plaque which they formed in the 5 weeks after the prophylaxis (Table 1). Two subjects were low plaque formers as only $0.5 \mathrm{mg}$ plaque per reference tooth was found. Twelve subjects were moderate to heavy plaque formers with $1 \cdot 6-7 \cdot 2 \mathrm{mg}$ plaque recovered per reference tooth. One subject was a rapid calculus former; his tooth surface deposits, including calculus, averaged $17.2 \mathrm{mg} /$ tooth. This distribution pattern suggested that at least three types of plaque formers were present in our sample. The subsequent clinical response to the placebo and kanamycin pastes bore this out. The low plaque formers had about $0.5 \mathrm{mg}$ plaques tooth at each of the succeeding 5-week intervals, indicating that neither the "no brushing" regime nor the treatment had an effect on the amount of plaque formed in these individuals. These subjects were excluded from the calculations (one subject was present in each group) because they did not possess the clinical problem, i.e. heavy plaque formation against which the therapy was directed. At the other end of the distribution was the boy who was a rapid calculus former. His tooth surface deposits were $10 \mathrm{mg} /$ tooth more than the next highest plaque former. Kanamycin treatment reduced these deposits by about 65 per cent, but did not prevent calculus formation. Even so, this subject averaged 4-5 mg plaque/tooth more than the other kanamycin treated subjects. He appeared to be an exceptional case not belonging to the rest of the study population. For this reason, it seemed justified to omit his data from the subsequent calculations and postulate that kanamycin might not be as effective in the management of oral health in those individuals who are rapid calculus formers. 
Thus the results which follow were confined to those subjects who were moderate to heavy plaque-formers. The amount of plaque in this population averaged about $3.2 \mathrm{mg} /$ tooth and exhibited a distribution curve which was skewed to the right or high side.

The effect that topical kanamycin had on 5-week-old plaque accumulations is shown in Table 2. At $\mathbf{0}$ time, the group destined to receive kanamycin averaged $2.9 \pm 1.8 \mathrm{mg}$ plaque wet weight per reference tooth, whereas the placebo group averaged $3.6 \pm 2.0 \mathrm{mg}$ plaque wet weight. An oral prophylaxis was given, and when the subjects returned 5 weeks later, no change in the plaque weight was noted. The kanamycin and placebo pastes were then applied in a double-blind procedure, and it was noted that some children showed an immediate clinical improvement. Five weeks later, when the subjects were re-examined, one group averaged $1.4 \pm 0.6 \mathrm{mg}$ plaque/ tooth and the other group averaged $4.1 \pm 1.7 \mathrm{mg}$. This intergroup difference was highly significant, (i.e. Student $t$-test, $p<0.01$ ), the group showing the improvement containing those children who had shown the immediate response. The code was broken, and these children were found to be the recipients of the kanamycin paste. Kanamycin treatment in these subjects thus had reduced the 5-week plaque mass by about 50 per cent when compared to this group's own pretreatment values. All of the subjects were retreated with nine applications of the respective pastes. Again, 5 weeks later, the kanamycin group showed a significant reduction when compared with the placebo group. The gingival condition of some children in the placebo group had deteriorated to pre-prophylactic levels, and a decision was made to treat this group also with kanamycin. At week 20 , with all subjects receiving kanamycin, there was no difference between the groups. However, the pre- and post-treatment values for the former placebo group, i.e. $3.9 \pm 1.4 \mathrm{mg}$ plaque wet weight vs $1.6 \pm 0.1 \mathrm{mg}$ plaque wet weight were significantly different, i.e. $p<0.05$. In subsequent weeks, the number of treatments was gradually reduced from nine to three without any loss of treatment effect. After week 30 , the subjects were considered as a single group and were maintained on only three applications of kanamycin every 5 th week until week 45. At this visit, no treatment was given and, when the subjects were examined at week 52 , their plaque accumulations had returned to pre-kanamycin levels (Table 2).

The effect of topical kanamycin on the UPS essentially paralleled its effect on the plaque wet weight and is shown in Table 3 . The prophylaxis had no discernible effect on the UPS. When kanamycin was applied after week 5 to the kanamycin group or after week 15 to the placebo group, a 20-30 per cent reduction in UPS occurred. Thus in the former group the UPS dropped from $1.8 \pm 0.3$ at week 5 , to $1.4 \pm 0.3$ at week 10 , and in the latter group from $2.1 \pm 0.3$ at week 15 to $1.4 \pm 0.1$ at week 20 . When antibiotic treatment was stopped, there was an increase in the UPS at week 52.

The GS differed from the wet weight measurement and the UPS in showing a residual effect of the prophylaxis (Table 4). The GS in the kanamycin group dropped from $1 \cdot 8 \pm 0.4$ just prior to the prophylaxis to $1 \cdot 5 \pm 0.5,5$ weeks after the prophylaxis. The kanamycin treatment then lowered the GS even further, so that scores of $1 \cdot 1 \pm 0.3$ and $1 \cdot 1 \pm 0.4$ were observed at weeks 25 and 30 . Thereafter, the GS increased at week 35 , primarily due to the transfer of two subjects who had low GS 
to another institution. In the placebo group, the GS dropped from $2 \cdot 3 \pm 0.5$ to $1.7+0.3$ as a result of the prophylaxis. In subsequent weeks, the GS increased with a value of $2.0 \pm 0.5$ recorded at week 15 . This GS was significantly higher than the $1.2 \pm 0.3$ value recorded in the kanamycin group (Student $t$-test, $p=0.02$ ). Because of the obvious clinical difference in the gingival health of the two groups, it seemed, for ethical reasons, unwarranted to continue the placebo treatment. The placebo subjects were given kanamycin and a gradual reduction in the GS over the next 10 weeks was observed. This reduction was not so impressive as compared to the effect that the kanamycin had on supragingival plaque wet weight and on the UPS. After kanamycin treatment was stopped, the GS also increased at week 52.

The data, thus far, were derived from the six reference teeth which had their supragingival plaque removed at each 5-week interval. The other teeth in the mouth appeared to show the same improvement as a result of kanamycin treatment as did these reference teeth. To substantiate this impression, the six opposite teeth, which

Table 5. Effect of Kanamycin on supragingival plaque accumulations and gingivitis SCORES AFTER 35 WEEKS OF INTERMTTENT APPLICATIONS OF KANAMYCIN

\begin{tabular}{llll}
\hline Time after prophylaxis & 0 week $\dagger$ & 5 weeks $\dagger$ & 40 weeks \\
\hline $\begin{array}{l}\text { Plaque wet weight per tooth }(\mathrm{mg}) \\
\text { Gingivitis scorc }\end{array}$ & $\begin{array}{l}3 \cdot 1 \pm 1 \cdot 7^{*} \\
1 \cdot 9 \pm 0.4\end{array}$ & $\begin{array}{l}3 \cdot 1 \pm 1 \cdot 1 \\
1 \cdot 5 \pm 0.4\end{array}$ & $\begin{array}{l}2 \cdot 1 \pm 1 \cdot 0 \\
1 \cdot 5 \pm 0.2\end{array}$ \\
\hline
\end{tabular}

* Average plus or minus standard deviation.

+ Values derived from teeth $3,9,12,19,25,28$.

$\ddagger$ Values derived from teeth $5,8,14,21,24,30$

corresponded to the reference teeth, were examined for plaque wet weight and gingivitis scores after having gone 40 weeks without brushing. These teeth averaged about $2 \mathrm{mg}$ plaque wet weight and had an average gingivitis score of 1.5 (Table 5). This plaque weight was about 1-2 mg less than usually found on unbrushed teeth in this population (Tables 2 and 5). The GS was similar to that found 5 weeks after the prophylaxis in the reference teeth (Table 5) and suggested that the gingival condition about these unbrushed teeth had not deteriorated in the subsequent 35 weeks of no oral hygiene. For comparison, the comparable teeth in the placebo group had gone from a GS of $1 \cdot 7,5$ weeks after the prophylaxis to a GS of $2 \cdot 0,15$ weeks after the prophylaxis (Table 4).

Repeated applications of any chemotherapeutic agent raise the possibility of the emergence of drug-resistant organisms and/or superinfection with yeast (SENECA, 1971 ; Mrtchell et al., 1967). During the course of this investigation, the yeast and the kanamycin-resistant bacteria present in plaque, and on the tongue, a site slightly removed from where the kanamycin was applied, were monitored. Table 6 shows that low levels of yeast were present at all times on the tongue, i.e. $7-41 \times 10^{2}$ organisms per tongue swab, and that no difference between the kanamycin and placebo groups could be recognized. Also the numbers of bacteria present on the tongue that were resistant to 0.05 per cent kanamycin did not change as a result of 
TABLE 6. EFFECT OF TOPICAL KANAMYCIN ON TONGUE FLORA

\begin{tabular}{|c|c|c|c|c|c|}
\hline & \multicolumn{5}{|c|}{ Time in weeks } \\
\hline & 5 & 10 & 15 & 20 & 25 \\
\hline & \multicolumn{5}{|c|}{ Yeast counts $\times 10^{2}$ per tonglie swab } \\
\hline $\begin{array}{l}\text { Kanamycin } \\
\text { Placebo }\end{array}$ & 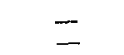 & $\begin{array}{l}9 \pm 12 * t \\
7 \pm 7\end{array}$ & $\begin{array}{l}29 \pm 26^{*} \\
40 \doteq 95\end{array}$ & $\begin{array}{l}27 \pm 19^{*} \\
10 \pm 12^{*}\end{array}$ & $\begin{array}{l}41 \pm 40^{*} \\
37 \pm 36^{*}\end{array}$ \\
\hline \multicolumn{6}{|c|}{$\begin{array}{l}\text { Bacteria resistant to } 0.05 \text { per cent kanamycin } \\
\text { counts } \times 10^{4} \text { per tongue swab }\end{array}$} \\
\hline $\begin{array}{l}\text { Kanamycin } \\
\text { Placebo }\end{array}$ & $\begin{array}{l}61 \pm 108 \dagger \\
97 \pm 123\end{array}$ & $\begin{array}{l}12 \pm 10^{*} \\
59 \pm 67\end{array}$ & $46 \pm 51 *$ & $\begin{array}{l}34 \pm 34^{*} \\
92 \pm 137^{*}\end{array}$ & $\begin{array}{l}11 \pm 12^{*} \\
35 \pm 43^{*}\end{array}$ \\
\hline
\end{tabular}

kanamycin treatment. In plaque, the yeast accounted for about 0.01 per cent of the cultivable flora and did not seem to change in number as a result of kanamycin treatment (Table 7). The number of bacteria resistant to 0.05 per cent kanamycin ranged from 6 to $83 \times 10^{5}$ organisms $/ \mathrm{mg}$ plaque wet weight, and represented about 6 per cent of the cultivable flora. Treatment with kanamycin did not increase their numbers.

TABle 7. EFFect of topical KaNamycin ON PLAQUe Flora

\begin{tabular}{|c|c|c|c|c|c|}
\hline & \multicolumn{5}{|c|}{ Time in weeks } \\
\hline & 5 & 10 & 15 & 20 & 25 \\
\hline \multicolumn{6}{|c|}{ Number of yeast $\times 10^{2} / \mathrm{mg}$ plaque wet weight } \\
\hline $\begin{array}{l}\text { Kanamycin } \\
\text { Placebo } \ddagger\end{array}$ & - & $\begin{array}{l}78 \pm 911^{*} \\
31 \pm 12\end{array}$ & $\begin{array}{c}109 \pm 93^{*} \\
26 \pm 42\end{array}$ & $\begin{array}{r}101 \pm 85^{*} \\
66 \pm 96^{*}\end{array}$ & $\begin{array}{l}96 \pm 57^{*} \\
31 \pm 54^{*}\end{array}$ \\
\hline \multicolumn{6}{|c|}{$\begin{array}{l}\text { Number of bacteria resistant to } 0.05 \text { per cent kanamycin } \\
\text { counts } \pm 10^{5} / \mathrm{mg} \text { plaque wet weight }\end{array}$} \\
\hline $\begin{array}{l}\text { Treatment group } \\
\text { Kanamycin } \\
\text { Placebo+ }\end{array}$ & $\begin{array}{l}83 \pm 38^{*} \\
52 \pm 34\end{array}$ & $\begin{array}{l}18 \pm 19+* \\
29 \pm 39\end{array}$ & $\begin{array}{l}31 \pm 42 * \\
67 \pm 87 \\
\end{array}$ & $\begin{array}{l}12 \pm 16^{*} \\
90 \pm 83^{*}\end{array}$ & $\begin{aligned} & 16 \pm 17^{*} \\
& 6 \pm 5^{*} \\
&\end{aligned}$ \\
\hline \multicolumn{6}{|c|}{ Percentage of viable bacteria resistant to 0.05 per cent kanamycin } \\
\hline $\begin{array}{l}\text { Treatment group } \\
\text { Kanamycin } \\
\text { Placebo } \neq\end{array}$ & - & $\begin{array}{l}2 \cdot 6 \pm 5 \cdot 00^{*} \\
8 \cdot 4 \pm 10 \cdot 9\end{array}$ & $\begin{array}{r}2.9 \pm 2 \cdot 8 * \\
11 \cdot 5 \pm 15.9\end{array}$ & $\begin{aligned} 1 \cdot 7 & \pm 2 \cdot 0^{*} \\
12 \cdot 4 & \pm 13 \cdot 4^{*}\end{aligned}$ & $\begin{array}{l}3 \cdot 3 \pm 1 \cdot 1^{*} \\
1 \cdot 2 \pm 1 \cdot 1^{*}\end{array}$ \\
\hline
\end{tabular}

\section{DISCUSSION}

The present investigation demonstrates that a topical antibiotic, such as kanamycin, can be used to improve the oral health of certain institutionalized Down's syndrome patients. No adverse clinical signs nor emergence of antibiotic-resistant organisms or yeast were observed during a 52-week period of treatment and observation. These results support and extend the findings of Mitchell et al. $(1965,1967)$ which showed that vancomycin applied topically could improve the oral health of anterior teeth of mentally retarded individuals. Together, these studies suggest that antibiotics used in certain situations may be of value in dental therapy. 
The use of antimicrobial agents in plaque control raises questions concerning (1) the clinical condition which should be treated, (2) the delivery of these agents to the plaque, and (3) the reasons why certain agents may be effective. The present investigation provides some guidelines which might help to formulate the most reliable and successful treatment approach possible.

The first consideration in the usage of antimicrobial agents is the selection of the disease situation to be treated. In medicine, antibiotics are used to treat and cure infections of bacterial aetiology. They have limited usefulness as prophylactic agents except in those situations where a high incidence of infection can be expected, e.g. bacteraemias following oral surgery, bowel surgery, etc., but, even here their value is equivocal (Johnstone, 1963; KarL, MertZ and Veith, 1966). In dentistry, when antibiotics were used to treat heavy plaque accumulations and associated gingivitis, they appeared to be successful, whether they were topically applied, e.g. vancomycin (MitChell and Holmes, 1965; MitChell et al., 1967), kanamycin (LOESCHE et al., 1971), or given systemically, e.g. spiromycin (Daligand, 1958; HarveY, 1961; WINER, COHEN and CHAUNCEY, 1966). However, when antibiotics were given prophylactically to prevent plaque formation on teeth that apparently did not exhibit periodontal involvement, the results have been equivocal (LöF et al., 1967; JFNSEN et al., 1968; VolPE et al., 1969; STALlaRd et al., 1969; LOBENE, BRION and SOCRANSKY, 1969; McFall, 1968). This failure of antibiotics to prevent plaque formation in normal volunteers, who have refrained from toothbrushing during the experimental period, and the possibility of increased plaque formation (JENSEN et al., 1968; LOBENE et al., 1969) have obscured the potential value of these agents in the far different situation that exists where periodontal disease is unchecked, such as occurs in the mouths of handicapped individuals. Yet, even in a population of handicapped persons, there will be individuals who do not need treatment because they do not have a disease condition, i.e. low plaque formers in the present study, and others, such as the subject who was a rapid calculus former, whose condition might be refractory to the agent chosen. Conceivably for calculus formers, the drug designated as $\mathrm{CC10232}$ which has been reported as capable of reducing calculus formation (VoLPE et al., 1969; STALLARD et al., 1969) might have been the agent of choice. From this it is apparent that some degree of clinical diagnosis and selection of drugs is necessary for optimal results with antibiotics. However, the chlorhexidine studies (LöE and Rindom ScHIotr, 1970; LöE, 1970) suggest that a single antimicrobial agent, if it is immediately bactericidal, broad-spectrum and capable of adsorption to dental structures (RoLLA, LöE and RiNDOM Schiotr, 1971), may overcome the problems inherent in matching the diseased situation with the most efficacious antibiotic. Chlorhexidine has been used for the prevention of supragingival plaque in "super clean" dental student volunteers (LÖE and RINDOM SCHIOTT, 1970). Its efficacy in the treatment of pre-existing periodontal conditions has not been reported, although FLotra et al., (1972) noted that where periodontal pockets of $3 \mathrm{~mm}$ or more were present, chlorhexidine was not effective in reducing the gingivitis. The failure in this case may be attributed to the inability of the chlorhexidine to penetrate the pocket depth, which is a failure of the delivery system and not necessarily the agent. 
Future studies of antimicrobial agents for plaque control should give high priority to the delivery of the agent to both supra and subgingival plaque for time periods adequate for optimal antibacterial action to occur. In the present study, the kanamycin paste was easily delivered to the supragingival areas by a cotton swab and had a profound effect on the subsequent mass of plaque which reformed in these sites. This manner of delivery would not reliably bring the kanamycin into contact with the subgingival plaque and, accordingly, the subgingival organisms were not inhibited to the same extent as the supragingival bacteria. Thus the subgingival plaque flora was undertreated, which could (1) account for the inability of the kanamycin to reduce the GS below 1.0, and (2) provide a reservoir of organisms which could recolonize the supragingival areas. The problem of gaining access to the subgingival plaque may be solved by combining topical antibiotic treatment with either mechanical pocket elimination as done by conventional periodontal procedures, or with systemic antibiotics. The choice of drugs, dosage and dose schedule will require empirical verification in order to obtain optimal clinical results.

The reasons for the residual effect of the kanamycin upon the supragingival plaque merits some attention. It is understandable that during the course of treatment the immediate reduction in plaque mass was due to the bactericidal effect of kanamycin on the plaque bacteria. When kanamycin was stopped, the plaque reformed, but it did not after 5 weeks reach the same bulk as was found previously in the pretreatment periods, or as was found in the placebo group. If it were simply a physical reduction in plaque that occurred during the period of kanamycin treatment, then the regrowth of plaque should have exhibited the same kinetics as that which followed the prophylaxis. This was not the case, as the prophylaxis had no discernable effect on 5-week plaque accumulations, indicating that, whatever alterations the prophylaxis caused in the microbial ecology of the supragingival plaque, they were of short duration. This would suggest that somehow the kanamycin had a persistent effect upon the plaque microbial ecology. This could come about if the kanamycin suppressed or eliminated certain bacterial species which contributed in unique ways to plaque bulk. This could be accomplished if the supragingival plaque contained bacteria such as Streptococcus mutans (GibBons et al., 1966), Actinomyces viscosis (JORDAN and KeYES, 1964), Actinomyces naeslundii (SOCRANSKY et al., 1970) or other diptheroids (HAGEAGE, JOHANSSEN and TANZER, 1970) which contributed, by the elaboration of an extracellular matrix, to plaque formation and bulk. With time, this residual kanamycin effect disappeared, as was seen by the regrowth of plaque at week 52 following 12 weeks of no treatment. This regrowth would suggest that the organism(s) responsible for plaque bulk had regained dominance either through recolonization from areas of the mouth from which they were not eliminated, i.e. subgingival plaque, or through re-infection from other children in the ward.

Acknowledgements - The assistance of Miss JANA LAIDLAW in the clinical aspects and Miss Arline Walenga in the bacteriological aspects of this study is gratefully acknowledged. This work was supported by a grant from the National Institute of Dental Research No. DE-03011-04. 
Résumé-Un petit groupe de malades avec le syndrome de Down, internés, ont été traités avec la pâte à sulphate de kanamycine, une ou deux fois par jour pendant 3-5 jours, chaque 5ème semaine sur une période de 52 semaines. Le poids humide de la plaque supragingivale dans le groupe traité avec kanamycine était significativement plus bas comparé avec la plaque supragingivale formée dans le groupe recevant une pâte témoin. Le nombre de gingivites dans le groupe traité avec kanamycine ne montra aucune détérioration pendant la période de l'administration antibiotique, en dépit de l'absence des procédés d'hygiène orale. Pendant la période de traitement avec kanamycine on n'a pas détécté une augmentation des bactéries résistantes ou des levures, dans les échantillons de la plaque ou de la langue.

Zusammenfassung-Eine kleine Gruppe von unter dem Down's Syndrom leidenden Anstalts-Patienten wurden mit örtlich aufgetragener Kanamycin-Sulphat-Salbe einmal oder zweimal täglich für 3-5 Tage behandelt, und zwar in jeder fünften Woche während eines Zeitraums von 52 Wochen. Während dieser 52 Wochen wurden die Zähne nicht gebürstet. Das Nassgewicht des Gaumenbelags war bei der mit Kanamycin behandelten Gruppe wesentlich herabgesetzt im Vergelich zu der mit einer simulierten Salbe behandelten Gruppe. Die Zahl der Entzündungen in der mit Kanamycin behandelten Gruppe stieg während der antibiotischen Behandlung nicht an trotz der Abwesenheit von mundhygienischen Massnahmen. Ebenso wurde eine Erhöhung von Kanamycin widerstehenden Bakterien oder Pilzen bei den Belag- oder Zungentests während der Kanamycin Behandlungsperiode nicht festgestellt.

\section{REFERENCES}

Brown, R. H., Levin, H. and Cunningham, W. M. 1961. Some dental manifestations of mongolism. Oral Surg. 14, 664-676.

Cutress, T. W. 1971. Periodontal disease and oral hygiene in trisomy 21. Archs oral Biol. 16, 13451355.

Daligand, P. 1958. Paradentosis-results of three years of Spiramycin therapy. Rev. Stomat. 59, 784-787.

Englander, H. R. and Keyes, P. H. 1971. Control of Streptococcus mutans, plaque, and dental caries in hamsters with topically applied vancomycin. Archs oral Biol. 16, 469-472.

Flotra, L., Giermo, P., Roli. a, G. and Waerhaug, J. 1972. A 4-month study on the effect of chlorhexidine mouth washes on 50 soldiers. Scand. J. dent. Res. 80, 10-17.

Gibrons, R. J., Berman, K. S., Knoettner, P. and Kapsimalis, B. 1966. Dental caries and alveolar bone loss in gnotobiotic rats infected with capsule forming streptococci of human origin. Archs oral Biol. 11, 549-560.

HAGeage, G. J., Johanssen, I. and TANZer, J. M. 1970. In vitro plaque formation by several oral diphtheroids implicated in periodontal disease. Infect. Immun. 2, 683-685.

H.ARVEY, R. F. 1961. Clinical impressions of a new antibiotic in periodontics: spiramycine. J. Can. dent. Ass. 27, 576-585.

Jensen, S. B., Löe, H., Schiott, C. R. and Theilade, E. 1968. Experimental gingivitis in man. 4. Vancomycin induced changes in bacterial plaque composition as related to development of gingival inflammation. J. periodont. Res. 3, 284-293.

JoHnStone, F. R. C. 1963. An assessment of prophylactic antibiotics in general surgery. Surg. Gynec. Obstet. 116, 1.

Jordan, H. V. and Keyes, P. H. 1964. Aerobic, Gram-positive, filamentous bacteria as aetiologic agents of experimental periodontal disease in hamsters. Archs oral Biol. 9, 401-414.

JoRdan, H. V. and DePaola, P. 1972. The inhibition of Streptococcus mutans by topical vancomycin treatment. Preprinted abstracts Intern. Ass. Dent. Res. 50th General Meeting Abstract 74.

JoRdan, H. V. and Hammond, B. F. 1972. Filamentous bacteria isolated from human root surface caries. Archs oral Biol. 17, 1333-1342.

Karl, R. C., Mertz, J. J., Veith, F. J. and Dineen, P. 1966. Prophylactic antimicrobial drugs in surgery. New Eng. J. Med. 275, 305-308.

Krasse, B., Jordan, H. V., Edwardsson, S. and Trell, L. 1968. The occurrence of certain "cariesinducing" streptococci in human dental plaque material with special reference to frequency and activity of caries. Archs oral Biol. 13. 911-918. 
Lobene, R. R., Brion, M. and Socransky, S. S. 1969. Effect of erythromycin on dental plaque and plaque forming microorganisms of man. J. Periodont. 40, 287-291.

LöE, H. 1967. The gingival index, the plaque index and the retention index systems. $J$. Periodant. $38,610-616$.

Löe, H., Theilade, E., Jensen, S. B. and Rindom Schiott, C. 1967. Experimental gingivitis in man. 3. Influence of antibiotics on gingival plaque development. J. periodont. Res. 2, 282-289.

Löe, H. and Rindom Schiotr, C. R. 1970. The effect of mouthrinses and topical application of chlorexidine on the development of dental plaque and gingivitis in man. J. periodont. Res. 5 , 79-83.

Löe, H. 1970. In: Dental Plaque (editcd by McHugh, W. D.) pp. 247-259. E. \& S. Livingstone, Edinburgh.

Loesche, W. J., Green, E., KeNNEY, E. B. and NAFE, D. 1971. Effect of topical kanamycin sulfate on plaque accumulation. J. Am. dent. Ass. 83, 1063-1069.

LoesChe, W. J. and GreEN, E. 1972. Comparison of various plaque parameters in individuals with poor oral hygiene. J. periodont. Res. 7, 173-179.

LoesCHE, W. J., HocketT, R. N. and SYED, S. A. 1972. The predominant cultivable flora of tooth surface plaque removed from institutionalized subjects. Archs oral Biol. 17, 1311-1326.

MCFALL, W. T. 1968. Effect of vancomycin on inhibition of bacterial plaque. J. dent. Res. 47, 1195.

Mitchell, D. F. and Holmes, L. A. 1965. Topical antibiotic control of dentogingival plaque. $J$. Periodont. 36, 202-208.

Mitchell, D. F., Holmes, L. A., Martin, P. W. and Saburai, E. 1967. Topical antibiotic maintenance of oral health. $J$. oral Therap. 4, 83-92.

RAMFJORD, S. 1959. Indices for prevalence and incidence of periodontal disease. J. Periodont. 30, $51-59$.

Rolla, G., LöE, H. and Rindom SchiotT, C. 1971. Retention of chlorhexidine in the human oral cavity. Archs oral Biol. 16, 1109-1116.

SENECA, H. 1971. Biological Basis of Chemotherapy of Infections and Infestations, pp. 87-104. F. A. Davis Co., Philadelphia.

Socransky, S. S., Hubersak, C. and Propas, D. 1970. Induction of periodontal destruction in gnotobiotic rats by a human oral strain of Actinomyces naeslundii. Archs oral Biol. 15, 993-995.

Stallard, R. E., Volpe, A. R., Ordan, J. E. and King, W. J. 1969. The effect of an antimicrobial mouth rinse on dental plaque, calculus and gingivitis. J. Periodont. 40, 683-694.

Swallow, J. N. 1964. Dental disease in children with Down's syndrome. J. ment. Defic. Res. 8, $102-118$

Syed, S. and LOESCHE, W. J. 1972. Survival of human dental plaque flora in various transport media. Appl. Microbiol. 24, 638-644.

Sznajder, N., Carraro, J. J., Otero, E. and Carranza, F. A. 1968. Clinical periodontal findings in trisomy 21 (Mongolism). J. periodont. Res. 3, 1-5.

Volpe, A. R., Kupczak, L. J., Brant, J. H., King, W. J., Kestenbaum, R. C. and Schlissel, H. J. 1969. Antimicrobial control of bacterial plaque and calculus and the effects of these agents on oral flora. J. dent. Res. 48, 832-841.

Winer, R. A., Cohen, M. M. and Chauncey, H. H. 1966. Antibiotic therapy in periodontal disease. J. oral Therap. 2, 403-410. 